\title{
Impact of Horse Age and Body Weight on the Angle Between the Parietal Surface of the Coffin Bone and the Ground
}

\author{
Malgorzata Dzierzęcka ${ }^{1}$, Sławomir Paśko ${ }^{2}$, Marcin Komosa ${ }^{3}$, Karolina Barszcz ${ }^{1}$ \\ Bartlomiej Jan Bartyzel ${ }^{1}$ and Ewa Czerniawska-Piątkowska ${ }^{4 *}$ \\ ${ }^{1}$ Faculty of Veterinary Medicine, Department of Morphological Science, Warsaw \\ University of Life Sciences, Nowoursynowska 166, 02776 Warsaw, Poland \\ ${ }^{2}$ Faculty of Mechatronics, Virtual Reality Technologies Department, The Institute of \\ Micromechanics and Photonics, Warsaw University of Technology, ul. Sw. Andrzeja \\ Boboli 8, 02525 Warsaw, Poland \\ ${ }^{3}$ Department of Animal Anatomy, Institute of Zoology, Poznan University of Life \\ Sciences, ul. Wojska Polskiego 28, 60637 Poznan, Poland \\ ${ }^{4}$ Department of Ruminant Science, West Pomeranian University of Technology, ul. \\ Klemensa Janickiego 29, 71-270 Szczecin, Poland
}

\begin{abstract}
A B S T R A C T
This study analyzed the impact of horse age and body weight on the angle between the parietal surface of the coffin bone and the ground. A precise description of the plantar margin and the inclination of the parietal surface of the bone may contribute to a better understanding of the biomechanics and strength of the hoof, in particular in horses with higher body weights. The study material included coffin bones of the thoracic limb, isolated post-mortem from 39 cold-blood horses. The study employed a scanner projecting a hybrid set of images, consisting of sinusoidal stripes preceded by a Gray code sequence, to perform the measurements. This method enabled the first objective assessment of the distribution of angles between the coffin bone parietal surface and the ground, which had not been possible using other imaging methods. The angle between the coffin bone parietal surface and the ground was found to be correlated with age, with a 0.27 correlation coefficient at $\mathrm{p}=0.1$, but not with body weight. The correlation coefficient for body weight was -0.08 at $\mathrm{p}=0.64$.
\end{abstract}

\begin{tabular}{l} 
Article Information \\
Received 29 April 2019 \\
Revised 29 July 2019 \\
Accepted 20 September 2019 \\
Available online 19 March 2021 \\
Authors' Contribution \\
\hline MD the initiator of the study who \\
conducted the main experimental \\
part, described the results, wrote the \\
article. SP performed the statistical \\
calculations, participated in drafting \\
of the manuscript. MK participated in \\
collecting the research material. KB, \\
BJB and ECP supervised the work. \\
Key words \\
Three-dimensional scanning, Third \\
phalanx, Coffin bone, Horses
\end{tabular}

\section{INTRODUCTION}

$\mathrm{I}^{\mathrm{n}}$ maging techniques used increasingly often in recent years, such as computed tomography (CT) or magnetic resonance imaging (MRI), opened up new possibilities in morphology studies (Dzierzęcka et al., 2008; Charuta et al., 2012; Dzierzęcka and Charuta, 2012a, b; Paśko et al., 2016). Modern devices for these techniques can provide new information, significantly contributing to better knowledge on the study subject (Pankowski et al., 2018a, b). Simultaneously, the past quarter-century saw rapid development of measurement systems based on three-dimensional optical scanning methods, including white light scanners (WLS). Three-dimensional scanning is primarily used in studies related to anatomy (Chen and Zhang, 2008; Ramsey, 2011; Yang et al., 2014). The earliest

\footnotetext{
Corresponding author: ewa.czerniawska-piatkowska@ zut.edu.pl 0030-9923/2021/0003-0895 \$ 9.00/0

Copyright 2021 Zoological Society of Pakistan
}

scanners, dating back to the 1970 s, were unidirectional. These were first used by Takasaki (1970), who recorder the image of the studied individual's back with a moiré pattern.

More advanced devices, allowing for more precise measurement, are structured-light optical scanners (Potsdamer and Altschuler, 1982). The scanner described by Potsdamer (Potsdamer and Altschuler, 1982) belongs to the category using a sequential projection of several rasters. These can be Gray codes, phase-shifted sinusoidal stripes, or binary codes; a hybrid method may also be used, applying both gray codes and sine stripes. The hybrid method was proposed in 1998, by Brenner et al. (1998). Two subgroups can be identified: one comprises devices termed "Rainbow 3D Cameras" (Geng, 1996), the other comprises devices projecting continually changing color stripes (Geng, 2004) Another group of scanners, rarely used commercially, operate based on the indexing of stripes (Zhang et al., 2002) or parts of the projected grid (Petriu et al., 2000). Selected methods can also be combined.

Three-dimensional scanning is primarily used for precise determination of the shape of objects that are 
difficult to measure. One example of such an object is the equine distal phalanx. This distinctive, complex-shaped bone fits within the hoof capsule, where it is located together with the distal part of the middle phalanx, the navicular bone, and soft tissue structures (Fig. 1).

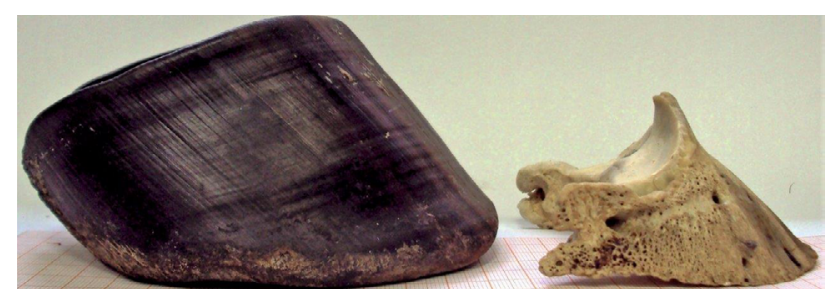

Fig. 1. Right thoracic coffin bone and hoof capsule; stallion, 6 years old, $505 \mathrm{~kg}$.

An understanding of normal hoof bone anatomy in horses of various breeds, morphological types, and ages, is prerequisite for the correct interpretation of any abnormalities. To date, most detailed studies on coffin bone anatomy focused on hot-blood horses (Linford et al., 1993; Vosugh et al., 2017). Publications on the broadlyunderstood normal phalangeal anatomy in cold-blood horses are still lacking. Authors analyzing the normal coffin bone anatomy in Arabian horses indicated the need to account for individual differences in result interpretation (Vosugh et al., 2017). Analyses were performed based on mediolateral radiographs of the distal phalanx, which had so far been considered the "gold standard" in the diagnosis of any alterations in the anatomy of this bone, both in live horses and post-mortem (Collins et al., 2011; Dzierzęcka et al., 2016; Vosugh et al., 2017).

The present study employed a scanner projecting a hybrid set of images, consisting of sinusoidal stripes preceded by a Gray code sequence, to perform the measurements (Sitnik et al., 2002; Paśko et al., 2017). By using the scanner, it was possible to study isolated coffin bones. Structured-light projection was used. Then, an analysis of the distribution of angles between the parietal surface of the bone and the ground was performed. The described measurements were performed in horses for the first time.

In horses subject to heavy use, a number of pathological processes in the hoof may occur with age. Problems developing within the hoof affect the condition of the corneous tissue of the hoof capsule. This is due to the fact that the surface of the coffin bone is covered with dermis and epidermal germinal layer, which produces the inner horn tissue of the hoof capsule. The body weight of a horse also affects the mechanical load on the phalanges, including in particular the coffin bone, during work. For these reasons, a precise description of the plantar margin and the inclination of the parietal surface of the coffin bone may contribute to a better understanding of the biomechanics and strength of the hoof in cold-blood horses.

\section{MATERIALS AND METHODS}

The study material included bilateral coffin bones of the equine thoracic limbs. The material was obtained from Polish Cold blood Horses used as draft horses (Dzierzęcka and Komosa, 2013). Animals of both sexes $(n=39)$ were sold from private farms to the Rawicz horse slaughterhouse for reasons unrelated to any musculoskeletal disorders. Their mean body weight was $577 \mathrm{~kg}$; min. $346 \mathrm{~kg}$, max. $793 \mathrm{~kg}$, age: $1-27$ years. Bones for analysis were isolated from limbs of randomly selected horses. Directive 2010/60/EU did not apply to this case, and hence, approval by the Local Ethics Committee for Animal Experiments was not required.

The coffin bone has a tapered crescent shape, with a concave plantar surface, palmar processes with a posterior orientation, and a rounded parietal surface with a shape that follows the outline of the hoof capsule (Schaller, 1992). Of note, it is the only bone that has no periosteum, or fibrous membrane on the exterior, which protects the bone and plays a role in nutrition, among other functions.

Figures 1 and 2 show examples of isolated bones with their hoof capsules.

Parts of the bilateral thoracic limb autopodia of the studied horses, together with the hoof, were separated by dissection of the pastern joint. Subsequently, each hoof was marked, and then boiled in water at $95-99^{\circ}$ for $48 \mathrm{~h}$. After boiling, the coffin bones were isolated out of the hoof capsule using standard anatomical dissection instruments, cleaned and dried at room temperature.

The isolated coffin bones were measured using a 3D scanner with a rotary table. The system comprised two 2 Mpix cameras placed at a distance of $500 \mathrm{~mm}$ from one another, and a pattern projector placed centrally between the cameras, with a resolution of $1280 \times 720$. The calibrated sample volume dimensions were 180 x $180 \mathrm{x}$ $100 \mathrm{~mm}$. Mean distance between measurement points in the measurement plane was $0.1 \mathrm{~mm}$, which was also the system's axial accuracy (Fig. 3).

Each study object was measured at 24 angles, which translates into a complete revolution with measurements performed every $15^{\circ}$. The rotary table allowed for angle positioning with a $0.025^{\circ}$ precision. Its surface was covered with anti-slip material to prevent any shifting of the object as the table moved. This eliminated the need for fastening the object to the table.

Each scan produced a point cloud. After preprocessing (removal of any artifacts), the data were 
analyzed so as to determine the distribution of angles between the parietal surface of the coffin bone and the ground. The angles were calculated within a single range for all the studied bones, which was $+/-1.833$ (7/12 $\pi$ ) radians, or $+/-105^{\circ}$. To visualize the angle distributions, the range was broken down into 100 parts, so that each part represented a segment of 0.0183 radians, or approximately $1^{\circ}\left(1.05^{\circ}\right)$. The coordinate system was centered on the highest point of the coffin bone - the extensor process. Areas with an angular width of $30^{\circ}(1 / 6 \pi)$ were analyzed, as shown in Figure 4.

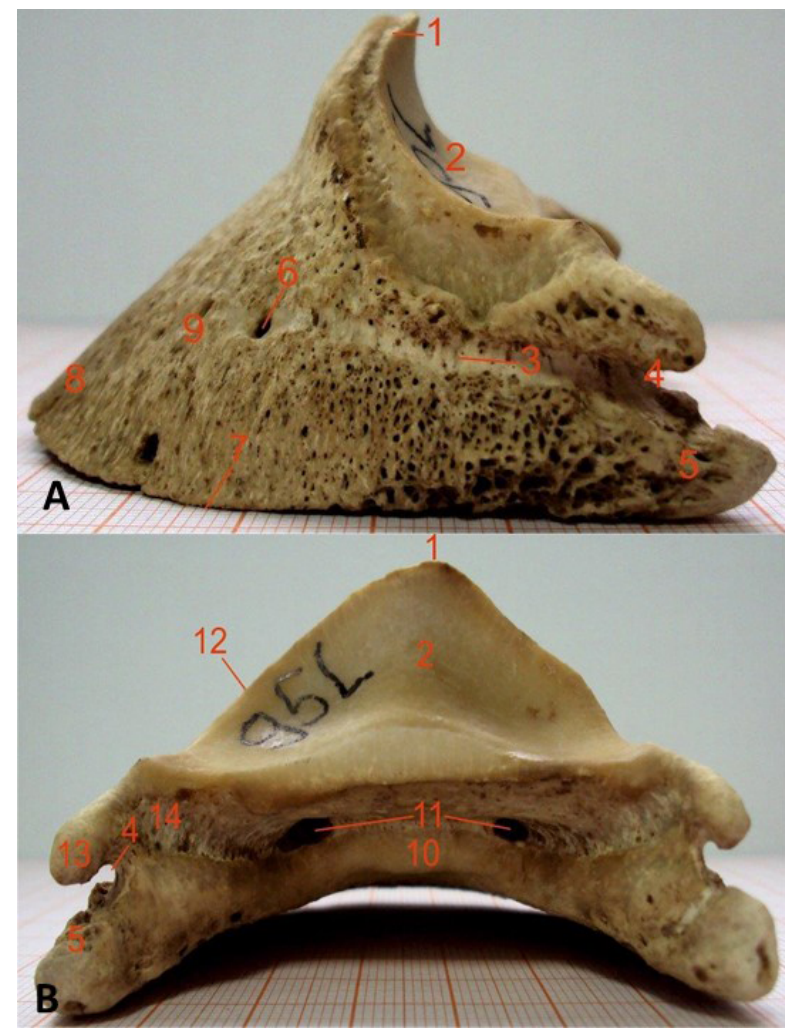

Fig. 2. Left distal phalanx (coffin bone, ungular bone) of a horse, phalanx distalis (os ungulare) (A) lateral aspect; (B) caudal aspect; mare, 6 years old, $479 \mathrm{~kg}$.

1 , extensor process, processus extensorius; 2 , articular surface, facies articularis; 3 , lateral parietal groove, sulcus parietalis lateralis; 4, notch of lateral palmar process, incisura processus palmaris lateralis; 5, 13. lateral palmar process, processus palmaris lateralis; 6 , parietal foramen, foramen parietale; 7, solar border, margo solearis; 8 , crena of solar margin. crena marginis solearis; 9 , parietal surface, facies parietalis; 10 , flexor surface, facies flexoria (the part of solar surface, facies solearis); 11, lateral and medial solar foramen, foramen soleare laterale et mediale (leading to solar canal, canalis solearis); 12 , coronary border, margo coronalis; 14, sesamoid articular surface, facies articularis sesamoidea.
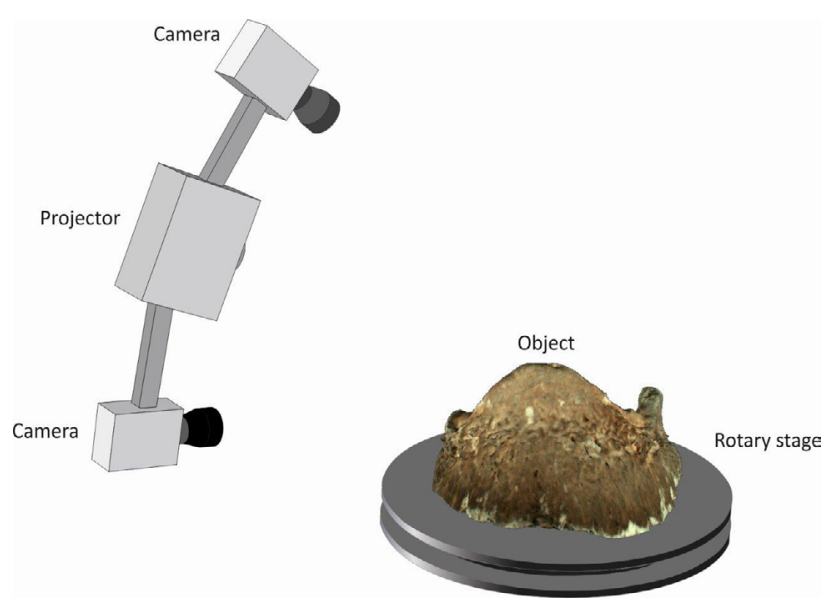

Fig. 3. Diagram of the scanning system used for coffin bone measurement.

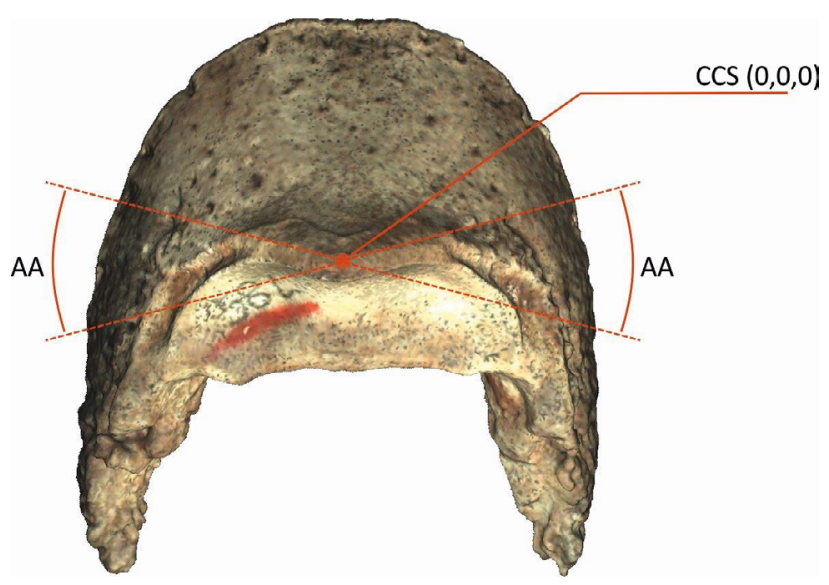

Fig. 4. Image of a bone with the specified area under analysis, CCS - center of coordinate system, AA - analyzed area.

The selection of the angle, and therefore the analyzed area of the coffin bone parietal surface, was motivated by several factors. First, the area was meant to be symmetrical about the straight line passing through the extensor process of the coffin bone, perpendicular to a line dividing the bone into two approximately similar areas. Second, the angle was required to be the same for all the analyzed bones. Some analyzed coffin bones differed considerably in their posterior part, due to a high variability of palmar process structure. Inclusion of this area would introduce a significant level of error into the calculations, and therefore, the analyzed area was restricted to the part of the parietal surface described above. Moving the study area excessively to the front of the bone was not advisable either, as in that case, only the angle for the front part of the parietal surface would be included in calculations. 
Table I. Shows angle between the medial and lateral surfaces within the study area, for bilateral coffin bones.

\begin{tabular}{|c|c|c|c|c|c|}
\hline No. & $\begin{array}{l}\begin{array}{l}\text { Age } \\
\text { (years) }\end{array}\end{array}$ & $\begin{array}{l}\text { Body weight } \\
\text { (kg) }\end{array}$ & $\begin{array}{l}\text { ADL } \\
\left({ }^{\circ}\right)\end{array}$ & $\begin{array}{l}\text { ADR } \\
\left({ }^{\circ}\right)\end{array}$ & $\begin{array}{l}\text { AD }=\mid \text { ADL }- \\
\mathbf{A D R} \mid\left(^{\circ}\right)\end{array}$ \\
\hline 1 & 1 & 491 & 7.9 & 4.0 & 3.9 \\
\hline 2 & 1 & 346 & 0.3 & 0.6 & 0.3 \\
\hline 3 & 2 & 543 & 0.9 & 4.0 & 3.1 \\
\hline 4 & 2 & 559 & 1.6 & 1.7 & 0.1 \\
\hline 5 & 3 & 424 & 9.0 & 2.5 & 6.5 \\
\hline 6 & 5 & 523 & 2.1 & 2.6 & 0.5 \\
\hline 7 & 6 & 362 & 10.1 & 13.2 & 3.1 \\
\hline 8 & 6 & 505 & 27.4 & 18.3 & 9.1 \\
\hline 9 & 7 & 586 & 2.6 & 3.0 & 0.4 \\
\hline 10 & 7 & 793 & 4.3 & 8.2 & 3.9 \\
\hline 11 & 8 & 748 & 2.8 & 21.9 & 19.1 \\
\hline 12 & 8 & 479 & 7.4 & 10.0 & 2.6 \\
\hline 13 & 10 & 602 & 0.3 & 5.1 & 4.8 \\
\hline 14 & 10 & 680 & 4.7 & 2.8 & 1.9 \\
\hline 15 & 10 & 651 & 0.2 & 4.3 & 4.1 \\
\hline 16 & 10 & 542 & 2.4 & 3.2 & 0.8 \\
\hline 17 & 11 & 515 & 25.2 & 7.6 & 17.6 \\
\hline 18 & 11 & 646 & 8.6 & 1.0 & 7.6 \\
\hline 19 & 12 & 549 & 6.8 & 5.2 & 1.6 \\
\hline 20 & 12 & 737 & 1.1 & 1.4 & 0.3 \\
\hline 21 & 12 & 652 & 0.7 & 2.0 & 1.3 \\
\hline 22 & 12 & 655 & 2.6 & 0.3 & 2.3 \\
\hline 23 & 13 & 549 & 7.3 & 7.6 & 0.3 \\
\hline 24 & 13 & 679 & 3.0 & 13.0 & 10 \\
\hline 25 & 14 & 865 & 1.1 & 0.7 & 0.4 \\
\hline 26 & 14 & 568 & 6.8 & 2.1 & 4.7 \\
\hline 27 & 17 & 608 & 3.3 & 1.1 & 2.2 \\
\hline 28 & 17 & 666 & 0.3 & 6.9 & 6.6 \\
\hline 29 & 18 & 366 & 2.0 & 10.9 & 8.9 \\
\hline 30 & 18 & 567 & 0.0 & 6.5 & 6.5 \\
\hline 31 & 18 & 584 & 5.5 & 1.7 & 3.8 \\
\hline 32 & 18 & 658 & 0.9 & 2.2 & 1.3 \\
\hline 33 & 19 & 646 & 17.0 & 8.4 & 8.6 \\
\hline 34 & 20 & 523 & 4.8 & 1.0 & 3.8 \\
\hline 35 & 23 & 543 & 14.8 & 5.4 & 9.4 \\
\hline 36 & 23 & 648 & 2.9 & 3.9 & 1 \\
\hline 37 & 25 & 484 & 3.9 & 14.4 & 10.5 \\
\hline 38 & 25 & 461 & 15.2 & 1.2 & 14 \\
\hline 39 & 27 & 501 & 9.0 & 4.1 & 6.5 \\
\hline
\end{tabular}

ADL (angle difference left bone) the parietal surface on the lateral and medial side of the left coffin bone. ADR (angle difference right bone) - difference between the inclination of the parietal surface on the lateral and medial side of the right coffin bone. $\mathrm{AD}$ (angle difference $\mathrm{AD}=|\mathrm{ADL}-\mathrm{ADR}|$ ) - difference between the differences calculated for the right and left coffin bones.

Analysis included points below the line marked in Figure 5. The analyzed area was selected deliberately.
Above this line, the parietal surface of the coffin bone features nutrient foramina and pores, which could distort calculation results, as the bone has multiple perforations due to the large number of blood vessels entering it. All this ensured that the analyzed fragments had a relatively homogeneous surface, similar for all the studied bones.
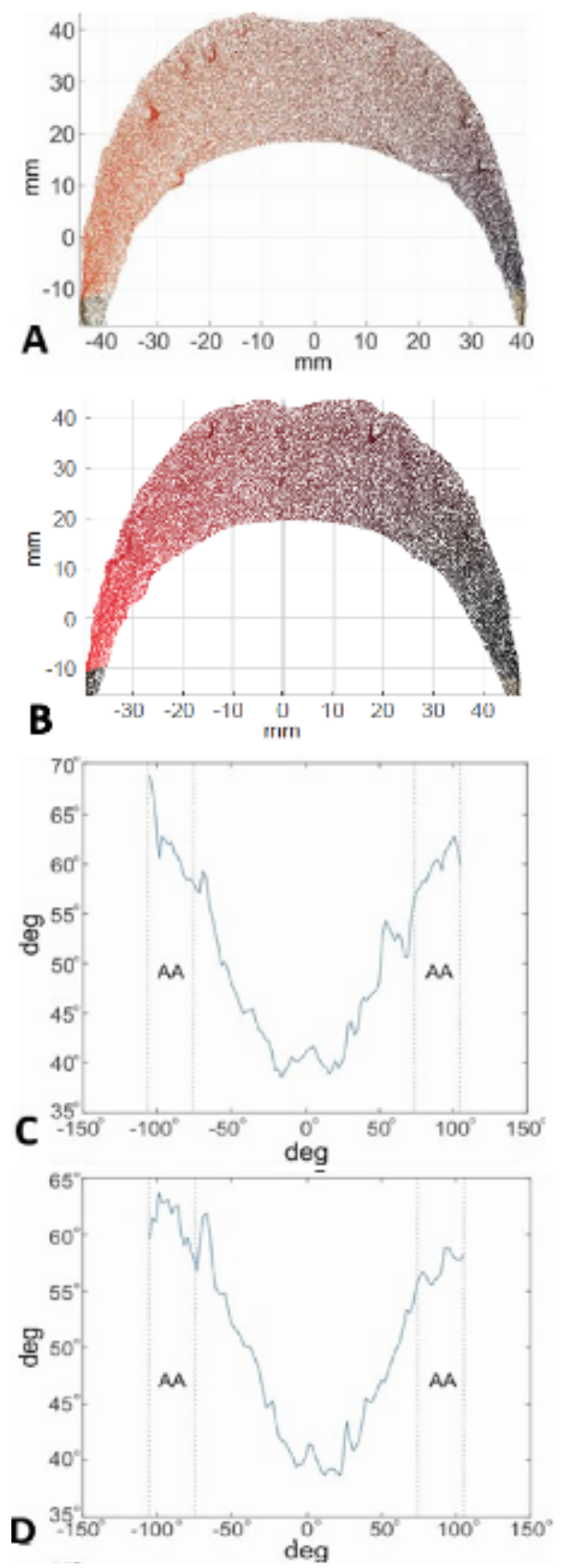

Fig. 5. a, b, c, d. Point cloud from the measurement in Figures (A), (B); distribution of angles on the parietal surface of a right and left coffin bone in Figures (C), (D) (gelding, 25 years old, $461 \mathrm{~kg}$ ), AA - analyzed area. 
Figures $5 \mathrm{~A}$ and $5 \mathrm{~B}$ show the analyzed area of the parietal surface on an example right and left coffin bone. The point clouds for the right and left bones are shown. Figures 5C and 5D show the calculated angles between the parietal surface of the coffin bone and the ground within these areas.

To calculate the angles of inclination of the parietal surface, first, a straight line was fitted to the points found in a specified area (Figs. 5A, B) by using singular value decomposition (SVD) and calculating the inclination of the first singular vector relative to a horizontal surface upon which the coffin bone rested. Fit within such a narrow angle range allowed for capturing the variation of angles, and for minimizing the impact of bone irregularities found in the distal part of the coffin bone.

The same SVD method was used to calculate the mean angle for the lateral and medial side of the coffin bone, and subsequently, to calculate the difference that reflected the mean angle between the analyzed surfaces. At this stage of analysis, the studied area of the coffin bone parietal surface was broken down into seven parts, each $0.5236(1 / 6 \pi)$ radians wide.

\section{RESULTS AND DISCUSSION}

By using the Shapiro correlation coefficient, the absolute difference in parietal surface inclination was found to be correlated with age, with a correlation coefficient of 0.27 at $p=0.1$, but not with body weight. This means that the coffin bone increasingly "spreads" to the sides with age, but body weight has no impact on this process. The correlation coefficient for body weight was -0.08 at $p=0.64$. As the distribution of data for right and left bones was not normal, they were compared using the Wilcoxon test. The results were: $\mathrm{W}=681, \mathrm{p}=0.6739$, which indicates that the distributions were different, i.e. the inclination of the parietal surface of the right and left coffin bones was asymmetrical.

The analysis also demonstrated that in the studied horse population, the parietal surface of the left coffin bone was inclined at an angle $0.33^{\circ}$ lower than the right, which means that the "spread" is more intense in this bone. Moreover, the angles were different for the lateral and medial part of the coffin bones, indicating that the coffin bone is not symmetrical about the medial plane.

So far, the anatomy of the equine distal phalanx had mainly been studied using imaging techniques, primarily radiography (Linford et al., 1993; Collins, 2011; Miyakoshi, 2017; Kilbourne and Hutchinson, 2019). Studies showed that the shape of the coffin bone is variable and dependent on a number of factors. The size and proportions of specific structures, both for the coffin bone and the other phalanges, is affected among other factors by the constitutional type, breed and genetic diversity (Dzierzęcka and Komosa, 2013; Vosugh et al., 2017). Coffin bone size is also related to the sizes of multiple other internal hoof structures, including both the adjacent bones and some soft tissue structures. Strong positive correlations were found primarily between the coffin bone characteristics and the width and thickness of the navicular bone (Komosa et al., 2013). This indicates a functional interrelation, as a large coffin bone creates favorable conditions for the function of the navicular bone and the deep digital flexor tendon. The proper function of the hoof also requires a well-developed frog, and in particular the part lying below the coffin bone-the digital cushion. Therefore, the shape of the coffin bone may favor a normal or abnormal morphology of the surrounding soft structures. Regarding the parietal surface of the coffin bone, its excessively vertical position relative to the heel causes the hoof wall to be steeper. Such morphology may cause dysfunction of the entire hoof, including imbalanced load on the phalangeal joints. On the other hand, an excessively inclined coffin bone may cause the angle between the hoof and the ground to be too low, which in turn causes increased deep digital flexor muscle tension.

For these reasons, researchers attempt to produce a precise description of the functional anatomy of the coffin bone and to establish factors associated with pathological alterations that develop within it. In 2017, the coffin bone was measured using a three-dimensional scanning technique for the first time (Paśko et al., 2017). The contactless measurement, providing information on the shape of the scanned object's surface, allows for analyses that would not have been possible with traditional measurement methods. Compared to CT, this measurement technique is considerably more accessible and costeffective. Moreover, it can be performed anywhere, as most three-dimensional scanning systems are mobile. This allows for performing measurements in places where the animals live. By using three-dimensional scanning, it was possible to precisely calculate the angle between the parietal surface of the coffin bone and the ground, and subsequently evaluate the impact of factors including horse age and body weight on this angle. Age was demonstrated to be associated with changes in the shape of the coffin bone. The angle between the coffin bone parietal surface and the ground was found to be correlated with age, but not with body weight.

In the studied population of horses, the shape of the coffin bone has changed with age. It consisted in a graual increase in the solar surface area of this bone while decreasingthe angle of inclination of the parietal surface of the bone to the substrate. This angle became sharper, 
and thus the coffin bone "flattened". Considering the fact that animals in the studied did not show any orthopedic changes, it might be considered that this phenomenon is physiological and refers not only to horses, but also to other ungulates. The scanning method can be used in in sport to monitoring the variation of the shape of the limbs due to training, in osteological research, for example in osteoarcheology.

\section{Statement of conflict of interest}

Authors have declared no conflict of interest.

\section{REFERENCES}

Brenner, C., Boehm, J. and Guehring, J., 1998. Photogrammetric calibration and accuracy evaluation of a cross-pattern stripe projector. Videometrics 6 SPIE, 3641:164-172.

Charuta, A., Dzierzęcka, M., Czerwiński, E., Cooper, R.G. and Horbańczuk, J.O., 2012. Sex - and age - related changes of trabecular bone of tibia in growing domestic geese (Anser domesticus). Folia Biol. (Krakow), 60: 205-212. https://doi. org/10.3409/fb60_3-4.205-212

Chen, S., Li, Y. and Zhang, J., 2008. Vision processing for realtime 3-D data acquisition based on coded structured light. IEEE Trans. Image Process., 17: 167-176. https://doi.org/10.1109/TIP.2007.914755

Collins, S.N., Dyson, S.J., Murray, C.R., Burden, F. and Trawford, A., 2011. Radiological anatomy of the donkey's foot: Objective characterisation of the normal and laminitic donkey foot. Equine Vet. J., 43: 478-486. https://doi.org/10.1111/j.20423306.2010.00312.x

Dzierzęcka, M. and Charuta, A., 2012a. The analysis of densitometric and geometric parameters of bilateral proximal phalanges in horses with the use of peripheral quantitative computed tomography. Acta Vet. Scand., 54: 41-51. https:// doi.org/10.1186/1751-0147-54-41

Dzierzęcka, M. and Charuta, A., 2012b. Comparision of the proximal phalanges in warmblood and coldblood horses with the use of peripheral quantitative computed tomography. Bull. Vet. Inst. Pulawy, 56: 637-642. https://doi.org/10.2478/ v10213-012-0112-3

Dzierzecka, M., Charuta, A., Wasowsk, A. and Bartyzel, B.J., Janiuk I., 2008. Injures of limb joints during race training of two-year-old thoroughbred horses. Bull. Vet. Inst. Pulawy, 52: 175-178.

Dzierzecka, M. and Komosa, M., 2013. Variability of the proximal phalanx in warmblood and coldblood horses - Morphological and structural analyses. Belg. J. Zool., 143: 119-130.

Dzierzęcka, M., Purzyc, H., Charuta, A., Barszcz, K., Komosa, M. and Kłosińska, D., 2016. Evaluation of distal phalanx formation and association with front hoof conformation in coldblooded horses. Biologia, 71: 337-342. https://doi.org/10.1515/ biolog-2016-0037

Geng, J., 2004. Method and apparatus for 3D imaging using light pattern having multiple sub-patterns. USA Patent no. US. pp. 937-948.

Geng, Z., 1996. Rainbow three-dimensional camera: new concept of high-speed three-dimensional vision systems. Opt. Eng., 35: 376-383. https://doi. org/10.1117/1.601023

Kilbourne, B.M. and Hutchinson, J.R., 2019. Morphological diversification of biomechanical traits: mustelid locomotor specializations and the macroevolution of long bone cross-sectional morphology. BMC Evol. Biol., 19: 37. https://doi. org/10.1186/s12862-019-1349-8

Komosa, M., Purzyc, H. and Frąckowiak, H., 2013. Changes in navicular bone (os sesamoideum distale) shape in horses as a result of pathological alterations. Folia Biol., 61:1-10. https://doi. org/10.3409/fb61_1-2.01

Linford, R.L., O'Brien, T.R. and Trout, D.R., 1993. Qualitative and morphometric radiographic findings in the distal phalanx and digital soft tissues of sound thoroughbred racehorses. Am. J. Vet. Res., 54: $38-51$.

Miyakoshi, D., Senba, H., Shikichi, M., Maeda, M., Shibata, R. and Misumi, K., 2017. A retrospective study of radiographic abnormalities in the repositories for thoroughbreds at yearling sales in Japan. J. Vet. Med. Sci., 79: 1807-1814. https://doi. org/10.1292/jvms.16-0425

Pankowski, F., Paśko, S., Max, A., Szal, B., Dzierzęcka, M., Gruszczyńska, J., Szaro, P. and Gołębiowski, M., Brtyzel B., 2018a. Computed tomographic evaluation of cleft palate in one-day-old puppies. BMC Vet. Res., 14:1-7. https://doi.org/10.1186/ s12917-018-1642-6

Pankowski, F., Bogiel, G., Paśko, S., Rzepiński, F., Misiewicz, J., Staszak, A., Bonecka, J., Dzierzęcka, M. and Bartyzel, B., 2018b. Fatal gunshot injuries in the common buzzard Buteo buteo L. 1758 imaging and ballistic findings. Foren. Sci. Med. Pathol., 14: 1-5. https://doi.org/10.1007/s12024018-0017-4

Parliament of the Republic of Poland: The Act of 21 August 1997 on the protection of animals. 
Dz. U. $1997 \mathrm{Nr} 111$ poz. 724 with modifications 2012. http://isap.sejm.gov.pl/etailsServlet?id=WDU19971110724

Paśko, S., Bartyzel, B.J., Dzierzęcka, M., Murawska, D., Szlufik, K., Bakoń, L., Gruszczyńska, J., Grzegrzółka, B. and Nowicki, M., 2016. Diagnostic application of Multirow computed tomography of the hip joint of Japanese quails (Coturnix Japonica). Braz. J. Poult. Sci., 18: 501-504. https:// doi.org/10.1590/1806-9061-2015-0217

Paśko, S., Dzierzecka, M., Purzyc, H., Charuta, A., Barszcz, K., Bartyzel, B.J. and Komosa, M., 2017. The osteometry of equine third phalanx by the use of three-dimensional scanning: New measurement possibilities. Scanning, 11:1-6. https://doi. org $/ 10.1155 / 2017 / 1378947$

Petriu, E.M., Sakr, Z., Spoelder, H.J. and Moica, A., 2000. Object recognition using pseudo-random color encoded structured light. Proceedings of the 17th IEEE Instrumentation and Measurement Technology Conference,

Posdamer, J.L. and Altschuler, M.D., 1982. Surface measurement by space-encoded projected beam systems. Computer Vision, Graphics, Image Process., 18: 1-17. https://doi.org/10.1016/0146664X(82)90096-X
Ramsey, G., 2011. Equine hoof biomechanics [dissertation]. Auckland Bioengineering Institute, The University of Auckland.

Takasaki, H., 1970. Moire topography. Appl. Opt., 9: 1467-1472. https://doi.org/10.1364/AO.9.001467

Schaller, O., 2011. Illustrated veterinary anatomical nomenclature Schaller. $2^{\text {nd }}$ edition. Stuttgard: Enke.

Sitnik, R., Kujawińska, M. and Woźnicki, J., 2002. Digital fringe projection system for large-volume 360-deg shape measurement. Opt. Eng., 41: 443449. https://doi.org/10.1117/1.1430422

Vosugh, D., Nazem, N.M. and Hooshmand, A.R., 2017. Radiological anatomy of distal phalanx of front foot in the pure Iranian Arabian horse. Folia Biol., 76: 702-708. https://doi.org/10.5603/FM.a2017.0028

Yang, G., Sun, C., Wang, P. and Xu, Y., 2014. Highspeed scanning stroboscopic fringe-pattern projection technology for three-dimensional shape precision measurement. Appl. Opt., 53: 174-183. https://doi.org/10.1364/AO.53.000174

Zhang, B., Curless, L. and Seitz, S.M., 2002. Rapid shape acquisition using color structured light and multi-pass dynamic programming. Proceedings of the 1st International Symposium on 3D Data Processing, Visualization and Transmission (3DPVT), Padova, Italy, pp. 24-36. 